\title{
Effect of tumor gangliosides on tyrosine phosphorylation of p125FAK in platelet adhesion to collagen
}

\author{
YI-XIN CHEN $^{1 *}$, XIAO-WEN CHEN ${ }^{2 *}$, CHANG-GANG LI $^{2}$, LI-JIE YUE ${ }^{2}$, HUI-RONG MAI ${ }^{2}$ and FEI-QIU WEN ${ }^{2}$ \\ ${ }^{1}$ Cancer Institute, the Second Clinical College of Medicine, Shenzhen People's Hospital, \\ Jinan University, Shenzhen, Guangdong 51802; ${ }^{2}$ Department of Hematology and Oncology, \\ Shenzhen Children's Hospital, Shenzhen, Guangdong 518026, P.R. China
}

Received August 17, 2012; Accepted September 28, 2012

DOI: $10.3892 /$ or.2012.2092

\begin{abstract}
The exact mechanisms as to how platelets influence blood-borne metastasis remain poorly understood. Gangliosides, sialic acid-containing glycosphingolipids, are associated with tumor progression and metastasis in humans. Gangliosides isolated from tumor cells promote collagenstimulated platelet aggregation and ATP secretion and enhance platelet adhesion to immobilized collagen. Gangliosides interact with a number of cell surface receptors including integrin receptors. In this study, we examined the effects of $\alpha_{2} \beta_{1}$ integrin-mediated platelet adhesion to collagen and phosphotyrosine signaling of focal adhesion kinase, p125FAK (FAK). Platelets pre-incubated with neuroblastoma tumor gangliosides (NBTGs) or their major component $\mathrm{GD}_{2}$ (disialoganglioside) were more adherent to immobilized collagen $\left(\mathrm{OD}_{570} 0.43 \pm 0.12\right.$, $0.39 \pm 0.13)$ compared to platelets pre-incubated with MTB $(0.14 \pm 0.06, \mathrm{P}<0.001)$; the effect of NBTGs was blocked by F-17 anti- $\alpha_{2}$ antibody. Pre-incubation of platelets with NBTGs resulted in a marked increase in the phosphotyrosine content of p125FAK in the adherent platelets compared to the MTB-preincubated adherent platelets. F-17 anti- $\alpha_{2}$ antibody decreased protein tyrosine phosphorylation of NBTG-incubated platelets adherent to collagen. These results indicate that the tumor gangliosides enhance platelet adhesion to extracellular matrix collagen by upregulating integrin $\alpha_{2} \beta_{1}$-mediated tyrosine phosphorylation of p125FAK, thereby providing insight into how this interaction may be involved in neuroblastoma metastasis.
\end{abstract}

\section{Introduction}

Tumor metastasis occurs through a multistep process (1). The interaction of circulating tumor cells that have detached from

Correspondence to: Dr Fei-Qiu Wen, Department of Hematology and Oncology, Shenzhen Children's Hospital, 7019 Yi Tian Road, Shenzhen, Guangdong 518026, P.R. China

E-mail: fwen62@126.com

*Contributed equally

Key words: ganglioside, integrin $\alpha_{2} \beta_{1}, \mathrm{p} 125 \mathrm{FAK}$, metastasis, neuroblastoma, platelet the primary tumor with structures of the tissue microvasculature is a crucial step preceding the invasion of the target organ. The specific events determining tumor cell interactions with endothelial cells during hematogenous metastasis are well defined (2); the role of other cell types such as platelets in this process, however, remains unclear.

Gangliosides, sialic acid-containing glycosphingolipids found in all eukaryotic cell membranes, play a role in cellcell interaction, as well as in cell growth and proliferation (3). Gangliosides interact with a number of cell surface receptors (4-8) including integrin receptors $(3,9)$. Neuroblastoma, an invasive, aggressive malignancy seen in children, is metastatic in $80 \%$ of patients at the time of presentation. Gangliosides are shed from the membrane of neuroblastoma cells into the extracellular milieu in large quantities. Gangliosides also affect platelet function. Gangliosides isolated from neuroblastoma tumor cells enhance platelet aggregation and activation and also promote platelet adhesion to extracellular matrix collagen (9-11). These effects are mediated through the integrin collagen receptor $\alpha_{2} \beta_{1}$. Gangliosides shed from the tumor may therefore represent a paracrine factor which, by virtue of its platelet activating activity, promotes metastasis.

Since gangliosides modify signals from receptor tyrosine kinases (12), they interact with integrins that signal via the tyrosine kinase mechanism (13) and regulate integrin-dependent cell adhesion and spreading by affecting $\alpha_{5} \beta_{1}$ signaling (14). One protein, focal adhesion kinase, p125FAK (FAK) localizes to focal plaques following cell adhesion to extracellular matrix (15). Its catalytic activity increases following cell adhesion to collagen (16). We speculated that tumor gangliosides might also modify the p125FAK signals generated by integrin in platelets. The present studies were undertaken to examine the effects of neuroblastoma tumor gangliosides (NBTGs) on $\alpha_{2} \beta_{1}$-mediated p125FAK signaling in platelets.

\section{Materials and methods}

Monoclonal antibodies. Murine anti-human monoclonal antibodies against p125FAK and phosphotyrosine residues, and goat anti-murine horseradish peroxidase-conjugated antibody used for immunoblotting were purchased from Transduction Laboratories (San Diego, CA, USA). For immunoprecipitation of p125FAK, murine anti-human monoclonal antibody was 
purchased from Upstate Biotechnology (Lake Placid, NY, USA).

Extraction and purification of tumor gangliosides. Total gangliosides were isolated from the neuroblastoma tumor cell line LAN-5 cells as previously described (17). Total lipids were extracted twice with 10 volumes of chloroform-methanol (1:1); the extracts were then combined and dried under a stream of $\mathrm{N}_{2}$, re-dissolved in a small volume of chloroform-methanol (1:1) and stored overnight at $-20^{\circ} \mathrm{C}$. Insoluble glycoproteins were removed by centrifugation $\left(1,000 \mathrm{xg}, 4^{\circ} \mathrm{C}\right)$ and the supernatant was dried under a stream of $\mathrm{N}_{2}$. The gangliosides were isolated by partitioning the dried total lipid extract in di-isopropyl ether/1-butanol/water (6:4:5, v/v) (4), followed by Sephadex G-50 gel exclusion chromatography to remove traces of salts and other low molecular weight contaminants and further purified by normal phase high pressure liquid chromatography. The $\mathrm{GD}_{2}$ (disialoganglioside) fraction was collected, lyophilized and re-purified by gel exclusion chromatography to remove salts. Gangliosides were quantified as nmol lipid bound sialic acid (LBSA) as previously described (18), separated by high performance thin layer chromatography (HPTLC) and visualized as purple bands following staining with resorcinol reagent (5).

Platelet isolation. Platelet donors abstained from all medications for a minimum of 7 days, fasted overnight and provided written, informed consent. Platelets were isolated from donors according to the methods previously described (11). In brief, blood was drawn into tubes containing acid-citrate dextrose-A to which $35 \mathrm{U} / \mathrm{ml}$ preservative-free heparin was added. Platelet-rich plasma was isolated by centrifugation $\left(3,000 \mathrm{x} \mathrm{g}, 15 \mathrm{~min}\right.$ at $\left.22^{\circ} \mathrm{C}\right)$ and then passed over Sepharose 2B (Amersham, Uppsala, Sweden) in modified Tyrode's buffer (MTB) in the absence of $\mathrm{Ca}^{2+}$ or $\mathrm{Mg}^{2+}$.

Platelet adhesion assay. Platelet adhesion was determined as previously described (17). Collagen was diluted with isotonic glucose ( $\mathrm{pH}$ 2.7-2.9) to a concentration of $40 \mu \mathrm{g} / \mathrm{ml}$. One hundred microliters of this suspension was used to coat the wells of a polystyrene microtiter plate (Falcon 3915, BectonDickinson) overnight at $22^{\circ} \mathrm{C}$. The wells were aspirated and blocked with $100 \mu \mathrm{l}$ of $0.5 \%$ BSA solution for $1 \mathrm{~h}$ at $22^{\circ} \mathrm{C}$ and then washed 3 times with MTB. Control wells were coated with BSA alone. Gel-filtered platelets were adjusted to $10^{5} / \mu 1$ in MTB without $\mathrm{MgCl}_{2}$ and incubated with purified tumor gangliosides at the specified concentration for $30 \mathrm{~min}$ at $37^{\circ} \mathrm{C}$ with gentle mixing. The platelets were washed once to remove unbound gangliosides and resuspended in MTB with $2.56 \mathrm{mM} \mathrm{MgCl} l_{2}$, and $100 \mu \mathrm{l}$ of the final platelet suspension was added to the wells and incubated for $1 \mathrm{~h}$ at $37^{\circ} \mathrm{C}$ with gentle mixing. The wells were vigorously washed 5 times with $100 \mu \mathrm{l}$ MTB to remove non-adherent platelets and loose aggregates. The number of adherent platelets was determined using the BCA assay (Pierce, Rockford, IL, USA) as previously described (17). Absorbance was measured at $570 \mathrm{~nm}$ $\left(\mathrm{OD}_{570}\right)$ with a microtiter plate reader (BioTek Instruments, Winooski, VT, USA). In each experiment, a standard curve of $\mathrm{OD}_{570}$ and platelet number was constructed by adding platelets $\left(10^{3}-10^{6}\right.$ per well) to collagen-coated, BSA-blocked wells as described above. An average $\mathrm{OD}_{570}$ value was calculated from triplicate wells over the range of platelet concentrations and related to direct phase-contrast microscopy counts by linear regression analysis. In all experiments, a direct correlation was observed between measured $\mathrm{OD}_{570}$ and platelet number $\left(r^{2}>0.95\right) . \mathrm{OD}_{570}$ values of $0.1,0.2,0.3$ and 0.4 represent platelet numbers of $1.76 \times 10^{3}, 1.57 \times 10^{4}, 1.39 \times 10^{5}$ and $1.26 \times 10^{6}$, respectively.

Effects of NBTGs on protein tyrosine phosphorylation of platelets adherent to collagen. The effects of NBTGs on protein tyrosine phosphorylation signaling through $\alpha_{2} \beta_{1}$ integrin were examined in platelets adherent to immobilized collagen. Collagen was diluted in isotonic glucose $(\mathrm{pH}$ 2.7-2.9) to a concentration of $100 \mu \mathrm{g} / \mathrm{ml}$ and $600 \mu \mathrm{l}$ of this suspension was used to coat the surface of 6-well plates (Falcon 1143, BectonDickinson, Oxnard, CA, USA) overnight at $22^{\circ} \mathrm{C}$. Wells were blocked with $0.1 \%$ BSA prior to adding platelets. Gel-filtered platelets $\left(10^{5} / \mathrm{ml}\right)$ were incubated with $1 \mu \mathrm{mol}$ NBTGs or $\mathrm{GD}_{2}$ dissolved in MTB with $2.56 \mathrm{mM} \mathrm{MgCl}_{2}$ and $100 \mathrm{mM} \mathrm{Na}_{3} \mathrm{VO}_{4}$ at $37^{\circ} \mathrm{C}$ for $30 \mathrm{~min}$. Then, $1.2 \mathrm{ml}$ of platelet suspension was added to the wells and incubated for $1 \mathrm{~h}$ at $37^{\circ} \mathrm{C}$ with gentle mixing. Non-adherent platelets were removed by aspiration, concentrated by centrifugation and lysed with ice cold lysis buffer (50 mM Tris, pH 8.0, $2.0 \mathrm{mM}$ EDTA, $0.15 \mathrm{M} \mathrm{NaCl}$, $1 \%$ Triton X-100, $200 \mathrm{mM} \mathrm{Na} \mathrm{VO}_{4}, 1 \mathrm{mM}$ PMSF, $1 \mu \mathrm{g} / \mathrm{ml}$ aprotinin and $1 \mu \mathrm{g} / \mathrm{ml}$ leupeptin) at $4^{\circ} \mathrm{C}$. Residual adherent platelets were lysed directly in the wells.

Immunoprecipitation. Protein lysates were incubated with washed Pansorbin cells (Calbiochem, La Jolla, CA, USA) for $30 \mathrm{~min}$ at $4^{\circ} \mathrm{C}$ with mixing. The sample was clarified $\left(12,000 \mathrm{x}\right.$ g for $15 \mathrm{~min}$ at $\left.4^{\circ} \mathrm{C}\right)$ and the protein recovered, then incubated overnight at $4^{\circ} \mathrm{C}$ with monoclonal antibody against p125FAK $(2 \mathrm{mg} / \mathrm{ml})$. To precipitate the p125FAK antibody complex, Protein G Plus-Agarose beads were added and the lysate was incubated for $4 \mathrm{~h}$ at $4^{\circ} \mathrm{C}$. The complex was then recovered and washed thrice with Triton X-100 lysis buffer. Immune complexes were boiled in equal volume of $2 X$ loading buffer for $2 \mathrm{~min}$ and the supernatant was recovered and immunoblotted.

Immunoblotting. Lysates were clarified by centrifugation $\left(12,000 \mathrm{xg}\right.$ for $15 \mathrm{~min}$ at $\left.4^{\circ} \mathrm{C}\right)$ and the supernatant was collected. Protein content in each sample was determined using the BCA assay. Western blotting of platelet lysates was performed with equal amounts of protein mixed with 1:1 vol of $2 \mathrm{X}$ loading buffer, then boiled at $100^{\circ} \mathrm{C}$ for $2 \mathrm{~min}$ and analyzed by 6 or $7.5 \%$ SDS-polyacrylamide gel electrophoresis. Proteins were transferred to a nitrocellulose membrane (Amersham) using a wet transfer module (Bio-Rad Laboratories, Hercules, CA, USA). Membranes were blocked with buffer A (1\% BSA or 5\% non-fat milk, $50 \mathrm{mM}$ Tris, $0.1 \%$ Tween- $20,100 \mathrm{mM} \mathrm{NaCl}$, $\mathrm{pH} 7.5)$ for $1 \mathrm{~h}$. The immunoblots were probed with anti-phosphotyrosine monoclonal antibody (PY-20) or anti-p125FAK monoclonal antibody $(1 / 1,000)$ in buffer $\mathrm{A}$ for $1 \mathrm{~h}$, washed and then incubated with HRP-conjugated secondary antibody $(1 / 1,000)$ for $1 \mathrm{~h}$. Proteins were visualized by enhanced chemiluminescence (ECL) and exposed to Hyperfilm ECL (Amersham). 


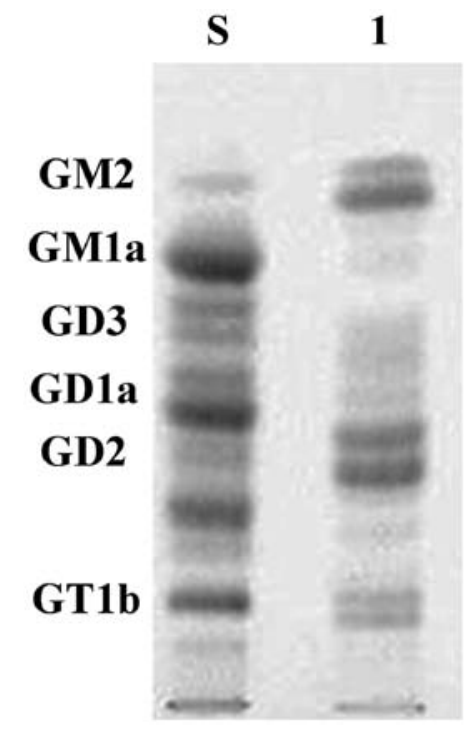

Figure 1. Chromatographic profile of gangliosides from LAN-5 cell lines. $\mathrm{S}$, standard gangliosides; lane 1, LAN-5.

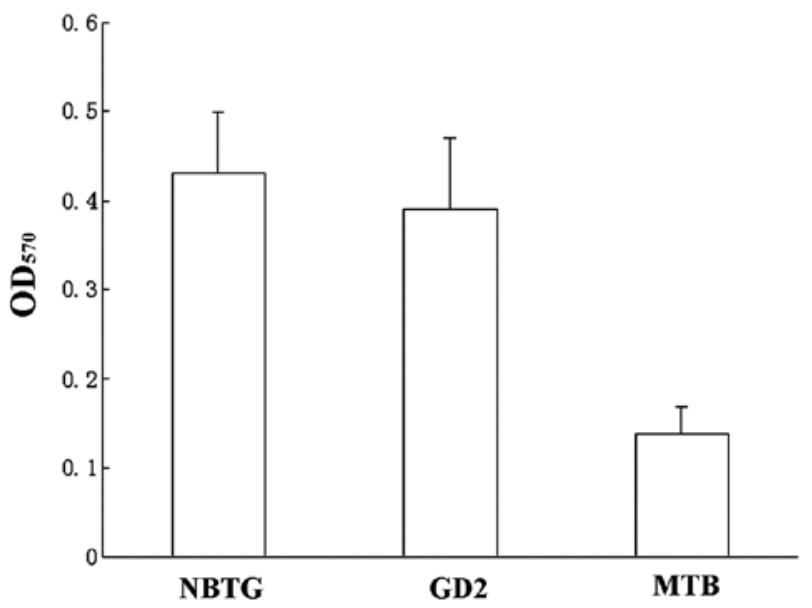

Figure 2. Effect of NBTGs on platelet adhesion to collagen. Gel-filtered platelets were pre-incubated with $1 \mu \mathrm{M} \mathrm{NBTGs}$ for $30 \mathrm{~min}$ at $37^{\circ} \mathrm{C}$ with gentle mixing. Unbound gangliosides were removed by centrifugation, and the final platelet product was resuspended to $10^{5} / \mu 1$ in MTB with $2.56 \mathrm{mM}$ $\mathrm{MgCl}_{2}$ The platelet suspension $(100 \mu \mathrm{l})$ was added to collagen-coated $(4 \mu \mathrm{g} /$ well), BSA-blocked wells and allowed to incubate for $1 \mathrm{~h}$ at $37^{\circ} \mathrm{C}$ with gentle mixing. Following removal of the non-adherent platelets, the residual adherent platelet number was estimated using the BCA assay. The mean and standard deviation of 4 experiments performed in 6 replicates is shown.

\section{Results}

Ganglioside compositions in LAN-5 neuroblastoma cell lines. The chromatographic profile of the LAN-5 cell line gangliosides is shown in Fig. 1. Human brain gangliosides (gift from Dr Zhengmei Zhu) were used as a standard. The predominance of $\mathrm{GD}_{2}$ is evident in the cell line, the other major composition is $\mathrm{GM}_{2}$, fewer compositions include $\mathrm{GD}_{3}, \mathrm{GT}_{1 \mathrm{~b}}$.

Neuroblastoma tumor gangliosides enhance $\alpha_{2} \beta_{1}$ integrinmediated platelet adhesion to collagen. In Fig. 2, platelets pre-incubated with $1 \mu \mathrm{mol}$ total NBTG or the major individual ganglioside $\mathrm{GD}_{2}$ were more adherent to immobilized collagen

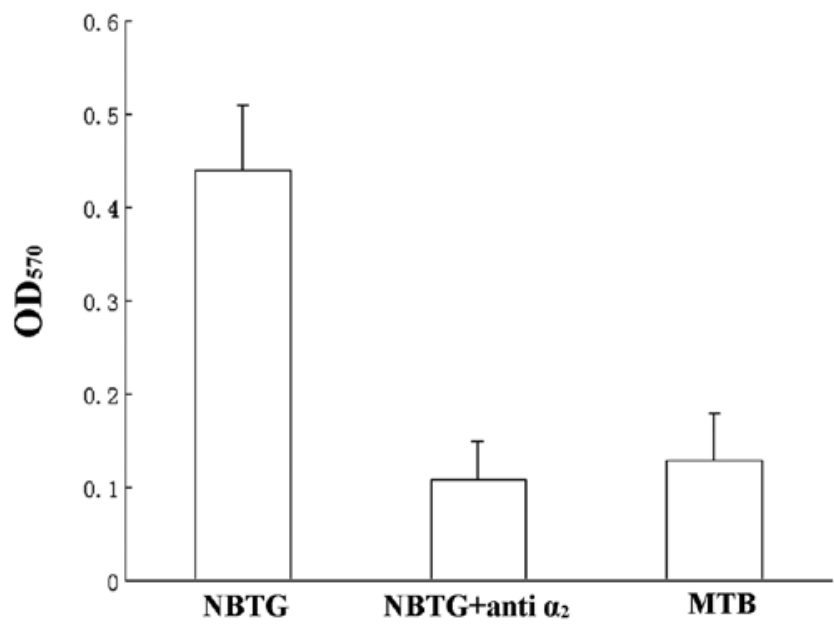

Figure 3. Effect of anti- $\alpha_{2}$ antibody on NBTG-enhanced platelet adhesion to collagen. Gel-filtered platelets were pre-incubated with $1 \mu \mathrm{M}$ NBTGs for $30 \mathrm{~min}$ at $37^{\circ} \mathrm{C}$ with gentle mixing. Unbound gangliosides were removed by centrifugation, and the final platelet product was resuspended to $10^{5} / \mu 1$ in MTB containing $10 \mu \mathrm{g} / \mathrm{ml} \mathrm{F-17} \mathrm{anti-} \alpha_{2}$ antibody and $2.56 \mathrm{mM} \mathrm{MgCl}$, then incubated for $30 \mathrm{~min}$ at $37^{\circ} \mathrm{C}$; excess antibody was not washed away. The platelet suspension $(100 \mu \mathrm{l})$ was added to collagen-coated $(4 \mu \mathrm{g} / \mathrm{well})$, BSAblocked wells and allowed to incubate for $1 \mathrm{~h}$ at $37^{\circ} \mathrm{C}$ with gentle mixing. Following removal of the non-adherent platelets, the residual adherent platelet number was estimated using the BCA assay. The mean and standard deviation of 4 experiments performed in 6 replicates is shown.

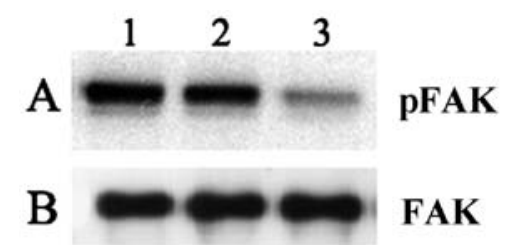

Figure 4. Effect of NBTGs and $\mathrm{GD}_{2}$ on tyrosine phosphorylation of platelets adherent to immobilized collagen. Gel-filtered platelets were pre-incubated with $1 \mu \mathrm{M}$ NBTGs and $\mathrm{GD}_{2}$ (lanes 1 and 2) for $30 \mathrm{~min}$ at $37^{\circ} \mathrm{C}$ or with MTB buffer (lane 3). The platelet suspension was added to collagen-coated $0.1 \%$ BSA-blocked wells and allowed to incubate for $1 \mathrm{~h}$ at $37^{\circ} \mathrm{C}$ with gentle mixing. Non-adherent platelets were removed, adherent platelets were lysed directly in the plates on ice using lysis buffer. An equal amount of protein was analyzed by SDS polyacrylamide gel electrophoresis and immunoblotting with anti-phosphotyrosine (A) and anti-p125FAK antibodies (B).

$\left(\mathrm{OD}_{570} 0.43 \pm 0.12,0.39 \pm 0.13\right)$ compared to platelets pre-incubated with MTB $(0.14 \pm 0.06, \mathrm{P}<0.001)$. Adhesion was maximal by $30 \mathrm{~min}$, and no further increase was observed with incubation duration up to $120 \mathrm{~min}$ (not shown). No effect of MTB on platelet adhesion to collagen was observed. $\alpha_{2} \beta_{1}$ integrin is the major collagen receptor on platelets, adhesion experiments were performed with anti- $\alpha_{2}$ monoclonal antibody to block the $\alpha_{2} \beta_{1}$ receptor. In Fig. 3 adhesion of NBTG-pre-incubated platelets was reduced to control levels by F-17 anti- $\alpha_{2}$ antibody $\left(\mathrm{OD}_{570} 0.11 \pm 0.05\right.$ vs. $\left.0.13 \pm 0.06 \mathrm{P}>0.05\right)$.

Effects of neuroblastoma tumor gangliosides on tyrosine phosphorylation of platelet adhesion to collagen. We examined the effects of NBTGs on phosphotyrosine signaling following platelet adhesion to immobilized collagen (Fig. 4). Adherent platelets were immunoprecipitated with anti-p125FAK anti- 


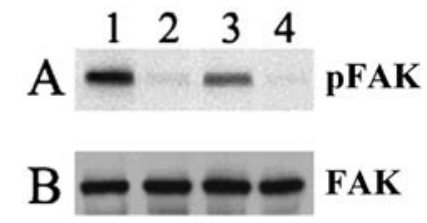

Figure 5. Effects of anti- $\alpha_{2}$ antibody on tyrosine phosphotyrosine content of NBTG-treated platelets adherent to immobilized collagen. Gel-filtered platelets were pre-incubated with $1 \mu \mathrm{M}$ NBTGs (lane 1), or with $1 \mu \mathrm{M}$ NBTGs plus $10 \mu \mathrm{g} / \mathrm{ml} \mathrm{F-17} \mathrm{anti-} \alpha_{2}$ antibody (lane 2) or with MTB buffer (lane 3), or with MTB buffer plus $10 \mu \mathrm{g} / \mathrm{ml} \mathrm{F}-17$ anti- $\alpha_{2}$ antibody (lane 4) for $30 \mathrm{~min}$ at $37^{\circ} \mathrm{C}$. The platelet suspensions were added to collagen-coated $0.1 \%$ BSAblocked wells and allowed to incubate for $1 \mathrm{~h}$ at $37^{\circ} \mathrm{C}$ with gentle mixing. Non-adherent platelets were removed, adherent platelets were lysed directly in the plates on ice using lysis buffer. The remainder of the experiment was performed as described in Fig. 4

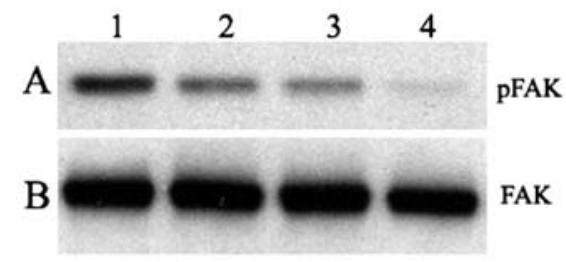

Figure 6. Effects of NBTGs on tyrosine phosphorylation of platelets adherent and non-adherent immobilized to collagen. Gel-filtered platelets were preincubated with $1 \mu \mathrm{M}$ NBTGs (lanes 1 and 2) or with MTB buffer (lanes 3 and 4) for $30 \mathrm{~min}$ at $37^{\circ} \mathrm{C}$. The platelet suspension was added to collagencoated $0.1 \%$ BSA-blocked wells and allowed to incubate for $1 \mathrm{~h}$ at $37^{\circ} \mathrm{C}$ with gentle mixing. Non-adherent platelets (lanes 3 and 4 ) were removed and sedimented then lysed and the protein isolated. Adherent platelets (lanes 1 and 2) were lysed directly in the plates on ice using lysis buffer. The remainder of the experiment was performed as described in Fig. 4.

body, then examined with an antiphosphotyrosine (Fig. 4A) or anti-p125FAK (Fig. 4B) antibody. The phosphotyrosine intensity of the p125FAK band (Fig. 4A) in platelets pre-incubated with NBTGs (lane 1) or $\mathrm{GD}_{2}$ (lane 2) was increased compared to MTB buffer-pre-incubated adherent platelets (lane 3). Total p125FAK protein content in each sample is comparable (Fig. 4B) and is not affected by gangliosides.

The effects of the gangliosides on tyrosine phosphorylation were explored in platelets adherent to immobilized collagen and in the non-adherent platelets (Fig. 5). Pre-incubation of platelets with $1 \mu \mathrm{M}$ NBTGs (lane 1) resulted in marked increases in the phosphotyrosine content of p125FAK (Fig. 5A) in the adherent platelets compared to the MTB-pre-incubated adherent platelets (lane 2); a similar, but less striking, effect of NBTGs on non-adherent platelets (lane 3) was observed, compared to MTB buffer-pre-incubated non-adherent platelets (lane 4). Total p125FAK protein content in each sample is comparable (Fig. 5B) and is not affected by the gangliosides.

NBTGs enhance the phosphotyrosine signaling through $\alpha_{2} \beta_{1}$ integrin following platelet adhesion to collagen. As we have shown NBTGs enhance $\alpha_{2} \beta_{1}$ integrin-mediated platelet adhesion to collagen, we further assessed this receptor's role in the phosphotyrosine signaling of NBTG-enhanced platelet adhesion to collagen by performing experiments in the presence or absence of an $\alpha_{2}$-blocking antibody F-17. In Fig. 6, F-17 anti- $\alpha_{2}$ antibody decreased protein tyrosinephosphorylation of NBTG-incubated platelets adherent to collagen (Fig. 6A). Adherent platelets pre-incubated with NBTGs and F-17 anti- $\alpha_{2}$ antibody (lane 2) had significantly reduced phosphorylation of p125FAK protein compared to adherent platelets pre-incubated only with NBTGs (lane 1). Total p125FAK protein content in each sample is comparable (Fig. 6B) and is not affected by the gangliosides.

\section{Discussion}

Both clinical and experimental evidence point to a role of platelets in the spread of cancer. Patients with metastatic disease reveal increased platelet counts and significantly elevated numbers of activated platelets (19). Depending on the type of tumor, various aspects of cancer progression may be affected by platelets, including tumor cell proliferation (20), tumor angiogenesis (21), vessel stability within tumors (22) or immune evasion $(23,24)$. Integrins, a widely expressed family of transmembrane adhesion receptors, represent a central determinant for physiological platelet function. GPIIb/IIIa is involved in both cell-cell adhesion and thrombus formation at the vascular wall, establishing it as a therapeutic target in vascular diseases (25). Pharmacological inhibition of GPIIb/IIIa has been demonstrated to reduce tumor cell metastasis, although the underlying mechanisms remain elusive (26). Similarly to GPIIb/IIIa results (14), Shield et al (27) reported that enhanced expression of $\alpha_{2} \beta_{1}$ integrin may influence spheroid disaggregation and proteolysis responsible for the peritoneal dissemination of ovarian carcinoma. Their findings raise the possibility that $\alpha_{2} \beta_{1}$ integrin may represent a valuable therapeutic target in the suppression of intra-peritoneal spread associated with the progression of ovarian cancer. The expression of $\alpha_{2} \beta_{1}$-integrin in peritoneal lesions was significantly increased compared with its expression in the primary lesion in the same individual. Peritoneal implantation of gastric carcinoma might be closely associated with $\alpha_{2} \beta_{1}$-integrin (28). Increasing evidence has implicated gangliosides, sialic acid-containing cell surface glycosphingolipids, in the biological and clinical behavior of many types of human tumor. Gangliosides are overexpressed and actively shed by tumor cells; they can bind to normal cells in the tumor microenvironment and have a number of biological properties that could conceivably alter tumor-host interactions to influence the survival of the malignant cells that carry these molecules. Collectively, these diverse observations reported in the literature have prompted us to investigate the modulation of platelet signaling by tumor gangliosides.

Gangliosides increase platelet aggregation, secretion (11) and adhesion (10). These activities are mediated through the collagen-binding integrin $\alpha_{2} \beta_{1}$ (9). NBTGs increase $\alpha_{2} \beta_{1^{-}}$ dependent platelet activation and adhesion (17). In this study, we also showed that NBTGs increase $\alpha_{2} \beta_{1}$-dependent platelet adhesion to immobilized collagen (Figs. 2 and 3 ) and increase intracellular phosphotyrosine signals following integrin ligation by immobilized ligand (Figs. 4-6).

Integrins, a widely expressed family of transmembrane adhesion receptors, represent a central determinant for physiological platelet function. A unique feature of integrins is the ability to regulate adhesive competence. The ability to bind ligand may be due to clustering into focal adhesions (29-31). An early event during integrin signaling is tyrosine phosphoryla- 
tion. Several protein tyrosine kinases have been implicated in integrin signaling events by virtue of their integrin dependent activation or their localization into focal contacts. p125FAK appears to play a central role in integrin-mediated signal transduction. This kinase is tyrosine phosphorylated and its tyrosine kinase activity is enhanced upon integrin-mediated engagement (32). Blood platelets contain high levels of tyrosine kinases $(33,34)$ and activation by various agonists including collagen leads to tyrosine phosphorylation of many proteins (16,35-37). Tyrosine phosphorylation of p125FAK has been demonstrated during thrombin or collagen-induced aggregation mediated by the $\alpha \mathrm{IIb} \beta 3$ integrin (38). Platelet activation leads to the upregulation of tyrosine kinases, including FAK (39). FAK, a 125-kDa cytosolic non-receptor tyrosine kinase, is associated with focal adhesion plaques of adherent cells such as fibroblasts and platelets (40). FAK is of particular interest, as it is considered a key intermediary of signaling through integrins $(31,41)$. The present study addresses the role of the collagen receptor $\alpha_{2} \beta_{1}$ in the regulation of FAK. Collagen activates FAK, as indicated by its tyrosine phosphorylation state. The antibodies against the $\alpha_{2}$ integrin, which prevent adhesion to collagen, block FAK activation, the results demonstrate that $\alpha_{2} \beta_{1}$ occupancy by collagen fibers regulate FAK. Our data suggest that $\alpha_{2} \beta_{1}$ ligation by immobilized ligand is capable of inducing phosphotyrosine signals.

Neuroblastoma, a neoplasm originating from neural crest cells, is the most common extracranial solid tumor of childhood. Gangliosides shed from neuroblastoma tumors are capable of enhancing platelet secretion, aggregation $(9,10)$, adhesion (42) and promote tumor cell migration and invasion (43). Our data show that neuroblastoma tumor gangliosides enhance integrin $\alpha_{2} \beta_{1}$ mediated platelet adhesion to type I collagen and the phosphorylation of pFAK125 provide an argument for a role of tumor gangliosides in metastasis. Jabbar et al (44) presented a 9-step model to explain the role of gangliosides in metastasis: gangliosides shed from tumor cells incorporate into the platelet membrane, then induce $\alpha_{2} \beta_{1}$ integrin clustering, clustered integrins interact with soluble collagen or with extracellular matrix collagen, intracellular signals (such as activation of focal adhesion kinase) are maximally generated when integrins are clustered and ligand is bound. These signals lead to cell-platelet adhesion, secretion, aggregation and promote tumor metastasis. Our results provide indirect evidence to confirm the model.

\section{Acknowledgements}

This study was supported by the grant S2011010004349 from the Natural Science Foundation of Guangdong Province and the Medical Key Subject of Health, Population and Family Planning Commission of Shenzhen Municipality (2011026).

\section{References}

1. Brooks SA, Lomax-Browne HJ, Carter TM, Kinch CE and Hall DM: Molecular interactions in cancer cell metastasis. Acta Histochem 112: 3-25, 2010.

2. Sahai E: Illuminating the metastatic process. Nat Rev Cancer 7: 737-749, 2007.

3. Yu RK, Tsai YT, Ariga T and Yanagisawa M: Structures, biosynthesis, and functions of gangliosides-an overview. J Oleo Sci 60 : 537-544, 2011.
4. Yates AJ, Saqr HE and Van Brocklyn J: Ganglioside modulation of the PDGF receptor. A model for ganglioside functions. J Neurooncol 24: 65-73, 1995.

5. Duchemin AM, Ren Q, Mo L, Neff NH and Hadjiconstantinou M: GM1 ganglioside induces phosphorylation and activation of Trk and Erk in brain. J Neurochem 81: 696-707, 2002.

6. Garofalo T, Misasi R, Mattei V, et al: Association of the deathinducing signaling complex with microdomains after triggering through CD95/Fas. Evidence for caspase-8-ganglioside interaction in T cells. J Biol Chem 278: 8309-8315, 2003.

7. Wang XQ, Sun P and Paller AS: Ganglioside induces caveolin-1 redistribution and interaction with the epidermal growth factor receptor. J Biol Chem 277: 47028-47034, 2002.

8. Singleton DW, Lu CL, Colella R and Roisen FJ: Promotion of neurite outgrowth by protein kinase inhibitors and ganglioside GM1 in neuroblastoma cells involves MAP kinase ERK1/2. Int J Dev Neurosci 18: 797-805, 2000.

9. Valentino LA and Ladisch S: Tumor gangliosides enhance alpha2 beta1 integrin-dependent platelet activation. Biochim Biophys Acta 1316: 19-28, 1996.

10. Fang LH, Lucero M, Kazarian T, Wei Q, Luo FY and Valentino LA: Effects of neuroblastoma tumor gangliosides on platelet adhesion to collagen. Clin Exp Metastasis 15: 33-40, 1997.

11. Valentino LA and Ladisch S: Circulating tumor gangliosides enhance platelet activation. Blood 83: 2872-2877, 1994.

12. Hakomori $\mathrm{S}$ and Igarashi Y: Functional role of glycosphingolipids in cell recognition and signaling. J Biochem 118: 1091-1103, 1995.

13. Hynes RO: Integrins: bidirectional, allosteric signaling machines. Cell 110: 673-687, 2002.

14. Wang XQ, Sun P and Paller AS: Ganglioside modulation regulates epithelial cell adhesion and spreading via ganglioside-specific effects on signaling. J Biol Chem 277: 40410-40419, 2002.

15. Hildebrand JD, Schaller MD and Parsons JT: Identification of sequences required for the efficient localization of the focal adhesion kinase, pp125FAK, to cellular focal adhesions. J Cell Biol 123: 993-1005, 1993.

16. Lipfert L, Haimovich B, Schaller MD, Cobb BS, Parsons JT and Brugge JS: Integrin-dependent phosphorylation and activation of the protein tyrosine kinase pp125FAK in platelets. J Cell Biol 119: 905-912, 1992.

17. Wen FQ, Jabbar AA, Patel DA, Kazarian T and Valentino LA: Atherosclerotic aortic gangliosides enhance integrin-mediated platelet adhesion to collagen. Arterioscler Thromb Vasc Biol 19: 519-524, 1999.

18. Wu G, Lu ZH, Wei TJ, Howells RD, Christoffers K and Ledeen RW: The role of GM1 ganglioside in regulating excitatory opioid effects. Ann NY Acad Sci 845: 126-138, 1998.

19. Wiesner T, Bugl S, Mayer F, Hartmann JT and Kopp HG: Differential changes in platelet VEGF, Tsp, CXCL12, and CXCL4 in patients with metastatic cancer. Clin Exp Metastasis 27: 141-149, 2010.

20. Wang Y and Zhang H: Platelet-induced inhibition of tumor cell growth. Thromb Res 123: 324-330, 2008.

21. Zaslavsky A, Baek KH, Lynch RC, et al: Platelet-derived thrombospondin-1 is a critical negative regulator and potential biomarker of angiogenesis. Blood 115: 4605-4613, 2010.

22. Ho-Tin-Noe B, Goerge T, Cifuni SM, Duerschmied D and Wagner DD: Platelet granule secretion continuously prevents intratumor hemorrhage. Cancer Res 68: 6851-6858, 2008.

23. Kopp HG, Placke T and Salih HR: Platelet-derived transforming growth factor-beta down-regulates NKG2D thereby inhibiting natural killer cell antitumor reactivity. Cancer Res 69: 7775-7783, 2009.

24. Nieswandt B, Hafner M, Echtenacher B and Mannel DN: Lysis of tumor cells by natural killer cells in mice is impeded by platelets. Cancer Res 59: 1295-1300, 1999.

25. Gawaz M and Geisler T: Coronary artery disease: platelet activity: an obstacle for successful PCI. Nat Rev Cardiol 6: 391-392, 2009.

26. Amirkhosravi A, Mousa SA, Amaya M, et al: Inhibition of tumor cell-induced platelet aggregation and lung metastasis by the oral GpIIb/IIIa antagonist XV454. Thromb Haemost 90: 549-554, 2003.

27. Shield K, Riley C, Quinn MA, Rice GE, Ackland ML and Ahmed N: Alpha2beta1 integrin affects metastatic potential of ovarian carcinoma spheroids by supporting disaggregation and proteolysis. J Carcinog 6: 11, 2007.

28. Matsuoka T, Yashiro M, Nishimura S, et al: Increased expression of $\alpha_{2} \beta_{1}$-integrin in the peritoneal dissemination of human gastric carcinoma. Int J Mol Med 5: 21-25, 2000. 
29. Clark EA and Brugge JS: Integrins and signal transduction pathways: the road taken. Science 268: 233-239, 1995.

30. Shattil SJ, Kashiwagi H and Pampori N: Integrin signaling: the platelet paradigm. Blood 91: 2645-2657, 1998.

31. Wang XQ, Sun $P$ and Paller AS: Inhibition of integrin-linked kinase/protein kinase B/Akt signaling: mechanism for ganglioside-induced apoptosis. J Biol Chem 276: 44504-44511, 2001.

32. Burridge K, Turner CE and Romer LH: Tyrosine phosphorylation of paxillin and pp125FAK accompanies cell adhesion to extracellular matrix: a role in cytoskeletal assembly. J Cell Biol 119: 893-903, 1992.

33. Golden A, Nemeth SP and Brugge JS: Blood platelets express high levels of the pp60c-src-specific tyrosine kinase activity. Proc Natl Acad Sci USA 83: 852-856, 1986.

34. Golden A, Brugge JS and Shattil SJ: Role of platelet membrane glycoprotein IIb-IIIa in agonist-induced tyrosine phosphorylation of platelet proteins. J Cell Biol 111: 3117-3127, 1990.

35. Haimovich B, Lipfert L, Brugge JS and Shattil SJ: Tyrosine phosphorylation and cytoskeletal reorganization in platelets are triggered by interaction of integrin receptors with their immobilized ligands. J Biol Chem 268: 15868-15877, 1993.

36. Polanowska-Grabowska R, Geanacopoulos M and Gear AR: Platelet adhesion to collagen via the alpha 2 beta 1 integrin under arterial flow conditions causes rapid tyrosine phosphorylation of pp125FAK. Biochem J 296: 543-547, 1993.

37. Smilowitz HM, Aramli L, Xu D and Epstein PM: Phosphotyrosine phosphatase activity in human platelets. Life Sci 49: 29-37, 1991.
38. Nakamura S and Yamamura H: Thrombin and collagen induce rapid phosphorylation of a common set of cellular proteins on tyrosine in human platelets. J Biol Chem 264: 7089-7091, 1989.

39. Gilmore AP and Burridge K: Molecular mechanisms for focal adhesion assembly through regulation of protein-protein interactions. Structure 4: 647-651, 1996.

40. Frangioni JV, Oda A, Smith M, Salzman EW and Neel BG: Calpain-catalyzed cleavage and subcellular relocation of protein phosphotyrosine phosphatase 1B (PTP-1B) in human platelets. EMBO J 12: 4843-4856, 1993.

41. Sun P, Wang XQ, Lopatka K, Bangash S and Paller AS: Ganglioside loss promotes survival primarily by activating integrin-linked kinase/Akt without phosphoinositide 3-OH kinase signaling. J Invest Dermatol 119: 107-117, 2002.

42. Meuillet E, Cremel G, Dreyfus H and Hicks D: Differential modulation of basic fibroblast and epidermal growth factor receptor activation by ganglioside GM3 in cultured retinal Muller glia. Glia 17: 206-216, 1996.

43. Zou CY, Wen FQ, Chen YX, Liu ZP and Zhang ZX: Effect of integrin alpha2beta1 on invasion and migration of neuroblastoma cells. Zhongguo Dang Dai Er Ke Za Zhi 10: 386-390, 2008 (In Chinese)

44. Jabbar AA, Kazarian T, Hakobyan N and Valentino LA: Gangliosides promote platelet adhesion and facilitate neuroblastoma cell adhesion under dynamic conditions simulating blood flow. Pediatr Blood Cancer 46: 292-299, 2006. 